\title{
The influence of moisture content on the polymer structure of polyvinyl alcohol in dispersion barrier coatings and its effect on the mass transport of oxygen
}

\author{
Åsa Nyflött, Çağlar Meriçer, Matteo Minelli, Ellen Moons, Lars Järnström, \\ Magnus Lestelius, Marco Giacinti Baschetti
}

(C) The Author(s) 2017. This article is an open access publication

\begin{abstract}
This paper presents a study of the effect of moisture on the gas permeability of polyvinyl alcohol $(\mathrm{PVOH})$ and $\mathrm{PVOH}-\mathrm{kaolin}$ dispersion barrier coatings. The oxygen permeability was measured at different humidity levels, and the material properties were characterized under the same conditions: polymer crystallinity, kaolin concentration, and kaolin orientation were all evaluated. The experimental results revealed that the water plasticizes the $\mathrm{PVOH}$ material of the coatings, and the presence of kaolin filler is unable to affect such behavior significantly. The PVOH crystallinity was affected drastically by the humidity, as water melts polymer crystallites, which is a reversible process under removal of water. The permeability data were analyzed using a thermodynamicbased model able to account for the water effect on both the solubility of the gas and the diffusivity coefficients in the polymer and composite. The results showed good agreement between the model's predictions and the experimental data in terms of the overall permeability of the material.
\end{abstract}

\footnotetext{
Å. Nyflött ( $\varangle)$, L. Järnström, M. Lestelius

Department of Engineering and Chemical Sciences,

Karlstad University, 65188 Karlstad, Sweden

e-mail: asa.nyflott@kau.se
}

\author{
Å. Nyflött \\ Stora Enso, Karlstad Research Centre, 65009 Karlstad, \\ Sweden \\ Ç. Meriçer, M. Minelli, M. G. Baschetti \\ Department of Civil, Chemical, Environmental and \\ Materials Engineering, Alma Mater Studiorum, University \\ of Bologna, 40131 Bologna, Italy \\ E. Moons \\ Department of Engineering and Physics, Karlstad \\ University, 65188 Karlstad, Sweden
}

Keywords Mass transport, Permeability, Modeling, Barrier coating, Moisture, Kaolin, PVOH

\section{Introduction}

Gas barriers are often employed to hinder the permeation of molecules through a material. In order to achieve the desired performance of the barrier, it is important to understand the mechanism of mass transport of the relevant species through the material. ${ }^{1,2}$ Filled polymer layers can be used as barrier coatings in the packaging industry. In this end-use application, it is important to be able to regulate the mass transport of, e.g., moisture, grease, and gases. Among the others, oxygen may be detrimental to the quality of packaged food, especially if the food contains lipids. ${ }^{3-5}$ Although the environmental conditions may affect the barrier performances over time, these should be withstood for the entire shelf life of the packaged product. It is essential that the material properties, and all factors affecting gas permeability, are well understood for the development of novel efficient barrier materials and the proper design of the existing ones.

Polymeric barrier materials are typically filled by impermeable inorganic fillers to improve their barrier performance. ${ }^{6,7}$ Polymer-based composite materials can be prepared by dispersion, interlamellar polymerization, or melting to provide not only enhanced barrier properties, but also better mechanical behavior and thermal stability. ${ }^{8,9}$ However, significant research efforts are still being devoted to the development of materials that can improve the performance and stability of the composite. ${ }^{10,11}$

The performance of the oxygen barrier depends on the nature of polymer and fillers used, as well as on processing conditions. ${ }^{12,13}$ For example, the suspensions used in dispersion coatings are usually water soluble, which makes them sensitive to moisture. 
Therefore, the qualitative and quantitative evaluation of the effect of the different processing parameters and environmental conditions on coating properties and performances is of paramount importance in obtaining a clear view of their performance and suitability for industrial development.

The permeation of gas through a barrier coating is affected by polymer properties, such as chain mobility, crystallinity, and free volume cavities. ${ }^{14}$ In the case of filled polymeric layers, the tortuous permeation pathways within the polymer are affected by the volume fraction and distribution (shape, size, and concentration) of the filler. Among the materials available in the field of dispersion coatings, polyvinyl alcohol (PVOH) is one of the most important; indeed, it has often been investigated alone or together with different fillers as to its suitability as a composite barrier layer. ${ }^{7,15} \mathrm{PVOH}$ has good film-forming properties and is a great $\mathrm{O}_{2}$ barrier, but has the drawback of being significantly water sensitive. The addition of clay can improve the barrier properties under humid conditions: the tortuous pathways introduced to the water molecules lower interaction with the polymer phase.

Recently, Nyflött et al. ${ }^{16}$ developed a modeling approach able to describe the gas solubility and diffusivity in polymer bases systems, and also to account simultaneously for the tortuosity effect produced by the addition of layered fillers. The penetrant solubility is evaluated making use of an equation of state (EoS) based model, which represents a wellestablished effective method for calculating the solubility of gases and vapors in amorphous polymer melts or rubbers. The nonequilibrium behavior of amorphous polymers has to be accounted for using the nonequilibrium thermodynamic model for glassy polymers (NET-GP), ${ }^{17,18}$ which provides the required extension of the EoS approach below $T_{\mathrm{g}}$. The model uses the lattice fluid EoS model by Sanchez and Lacombe $^{19}$ in combination with the NET-GP approach, giving rise to the so-called nonequilibrium lattice fluid (NELF) model. ${ }^{17}$ The NELF model is able to represent the solubility of gases and vapors in amorphous glassy polymers; the lattice fluid model is combined with the simple transport model, as done previously by others. ${ }^{20-27}$

The diffusivity of the penetrants has to be analyzed too and described by an appropriate transport model. The diffusional behavior of the penetrant in the polymer matrix is related to the penetrant size and the diffusion sites available. Semicrystalline polymers force the penetrant to take a tortuous path around the often impermeable crystalline regions, which affects both diffusivity and solubility.

Tortuous paths produced by platelet-like fillers, e.g., clay, have been studied extensively by many groups by analytical solutions with a simplified geometry, numerical calculations based on ordered or random structures or molecular simulations. ${ }^{6,28-51}$ The addition of filler can enhance the barrier function of polymer films since it introduces regions that are impermeable to gases, and the diffusional pathways for the penetrating molecules may be significantly enhanced.

The aim of this study was to investigate the effect of moisture on the barrier properties of $\mathrm{PVOH}$ and PVOH-kaolin composites, namely filler dispersion, barrier structure, and barrier performance. The permeability was measured at different $\mathrm{RH}$ in the range of $0-80 \%$. The barrier structure was affected by humidity and kaolin concentrations. A model was also built to describe the behavior of the materials by combining different models that are able to account independently for the effect of gas solubility, filler dispersion, polymer crystallinity, and humidity on the barrier properties of the composite material.

\section{Materials and methods}

\section{Materials}

The barrier layer used in this study was made from PVOH (Mowiol 15-99 from Kuraray, Frankfurt, Germany) and kaolin (IMERYS, Sandersville, USA). The kaolin particles were received pretreated with sodium polyacrylate (NaPAA). The size distribution of the kaolin platelets had previously been determined to be in the range $0.1-5 \mu \mathrm{m}$ (width and length) ${ }^{52}$; according to the supplier, the completely separated platelets had a width-/length-thickness ratio of 60 (corresponding to an aspect ratio 16 , according to the definition adopted in this work: surface area of the plane divided by surface area of side surface). PET sheets $(23-\mu \mathrm{m}$ thick) purchased from HiFi Industrial Films (Hertfordshire, UK) served as the coating substrate; their even thickness and high adhesion strength to the $\mathrm{PVOH}$ coating made them very suitable for this purpose. ${ }^{53}$

\section{Preparation of $\mathrm{PVOH}$, kaolin dispersions and coatings}

PVOH was dissolved in deionized water at $95^{\circ} \mathrm{C}$ under gentle stirring for $1.5 \mathrm{~h}$ and then cooled to room temperature before film preparation or being mixed with kaolin. The kaolin clay was dispersed in deionized water by high-shear mixing to a concentration of 60 $\mathrm{wt} \%$. Once this process was complete, the dispersion was stirred at a lower speed for $30 \mathrm{~min}$ before being diluted to the concentrations required to receive the target concentration in the dry state. Finally, the $\mathrm{pH}$ was adjusted to 6.8. Aqueous suspensions, based on $\mathrm{PVOH}$ and water solutions of kaolin, were prepared and coated onto the PET films according to the procedure described below. ${ }^{54}$

The dispersion was drawn down on the PET sheets with a bench rod coater (K202 Control Coater, RK Print Coat Instruments Ltd., Royston, UK) and subsequently dried at $95^{\circ} \mathrm{C}$ in a heating chamber until the barrier coatings contained only $5 \%$ water. The barrier 
coating reached temperatures of approximately $70^{\circ} \mathrm{C}$ during drying, as measured by an IR temperature sensor (Thermopoint TPT 62, FLIR system AB, Danderyd, Sweden). The water content in the barrier during drying was measured with a contactless NIR moisture sensor (FIBRO MCA 1410, FIBRO System AB, Hägersten, Sweden).

The dried weight proportions of the dispersions and the measured crystallinity in nonconditioned samples are given in Table 1. The thickness was measured mechanically using a micrometer screw (Mitutoyo micrometer, $\pm 0.5 \mu \mathrm{m}$ resolution, Mitutoyo Scandinavia $\mathrm{AB}$, Väsby, Sweden) measuring the thickness at six positions of the sample; the PET substrate was found to have a thickness of $22 \pm 0.1 \mu \mathrm{m}$, and that of the coating resulted $4 \pm 2 \mu \mathrm{m}$ (measured together with PET).

\section{Permeability methods}

Permeability measurements were taken in two different setups (manometric permeometer and ambient oxygen ingress rate, described below). In all of the methods, a sample was introduced and monitored until steady-state permeation was reached. The uncertainty of the steady-state permeability was estimated as being less than $10 \%$ of the reported values, which then includes both the error from the permeability measurement and the coating thickness. Figure 1 shows the layout of the pressure-based permeometer, used to measure the oxygen permeability at various humidity levels from dry to about $80 \%$ RH. ${ }^{55,56}$ The system measures the amount of gas permeated through the polymer sample by monitoring the pressure increase in a calibrated volume compartment ASTM. ${ }^{57}$

The experimental procedure (Fig. 1) began by mounting the specimen in the sample holder and carefully, under vacuum, removing the residual water and gases absorbed in the sample for a minimum of 2 days in order to rid the polymer of all the residual substances it had absorbed. In the case of the dry experiments, the system was then ready for the tests. The upstream compartment was filled with the desired gas, and the pressure increase was monitored in the downstream gas resulting from permeation across the sample. In case of the humid gas experiments, the sample was equilibrated to the desired $\mathrm{RH}$ by exposing it to pure water vapor at the correct pressure. Then a gas stream at the same RH was fed to the upstream side of the film, and the pressure downstream was monitored, as in dry experiments. More information on the two experimental setups, as well as the measuring techniques, can be found elsewhere. ${ }^{55,56}$

The ambient oxygen ingress rate (AOIR) measures the oxygen increase in a cell; the humidity in the cell is controlled by a salt solution. The AOIR measurements are taken using a zirconium sensor instead of a pressure sensor. ${ }^{38}$ In this case, both sides of the cell are flushed either with air (upstream) or nitrogen (downstream). The sensor measures the increase in oxygen concentration on the downstream side, which is used to calculate the permeate flow. This setup, shown in Fig. 2, therefore uses oxygen from the atmosphere ( $20.9 \%$ oxygen) rather than the pure $(100 \%)$ oxygen that a permeometer uses.

All permeability measurements were taken at $35^{\circ} \mathrm{C}$. The permeability, $P$, of the pressure-driven permeometer was calculated using the following expression:

$P=\left(\frac{d p}{d t}\right)_{t \rightarrow \infty} \frac{V}{R T A} \frac{\tau}{\Delta p}$

where $V$ is the cell volume, $T$ is the temperature, $A$ is the area, $p$ is the pressure, $t$ is the time and $\tau$ is the thickness of the sample. The permeability from the AOIR measurements was calculated according to:

$P=\left(\frac{d c}{d t}\right)_{t \rightarrow \infty} \frac{V \cdot R \cdot T \cdot \tau}{V_{\mathrm{gas}(\mathrm{STP})} \cdot p_{\mathrm{atm}} \cdot A}$

where $c$ is the concentration in the downstream compartment and $p_{\text {atm }}$ is the difference in the partial pressure of oxygen across the sample $(0.21 \mathrm{~atm})$. The permeation areas and downstream volumes were $A=9.6 \mathrm{~cm}^{2}$ and $V=26.34 \mathrm{~cm}^{3}$ (dry tests) and $V=15 \mathrm{~cm}^{3}$ (humid tests) for the manometric apparatus, while and $A=5 \mathrm{~cm}^{2}$ and $V=225 \mathrm{~cm}^{3}$ for the AOIR apparatus.

The oxygen permeability was measured on multilayer samples with PET substrates, and its permeability was found to equal $2.9 \times 10^{-17} \pm 0.3 \mathrm{~mol} \mathrm{~s}^{-1} \mathrm{~m}^{-1}$ $\mathrm{Pa}^{-1}$ (the error is given in standard deviation). The permeability of the coating only had been calculated using the well-known resistance series formula ${ }^{59}$ :

Table 1: Different samples dry content of PVOH and kaolin and measured crystallinity in nonconditioned samples $\mathrm{PVOH}$ content/wt\% Kaolin content/wt\% Degree of crystallinity/\%

\begin{tabular}{llr}
\hline 100.0 & 0 & $47.0 \pm 0.5$ \\
98.9 & 1.1 & $37.1 \pm 5.3$ \\
97.0 & 3.0 & $43.5 \pm 0.2$ \\
95.0 & 5.0 & $48.1 \pm 0.4$ \\
89.8 & 10.2 & $40.9 \pm 0.2$ \\
80.0 & 20.0 & $45.1 \pm 0.5$ \\
\hline
\end{tabular}






Fig. 1: Schematic diagram of a manometric permeometer
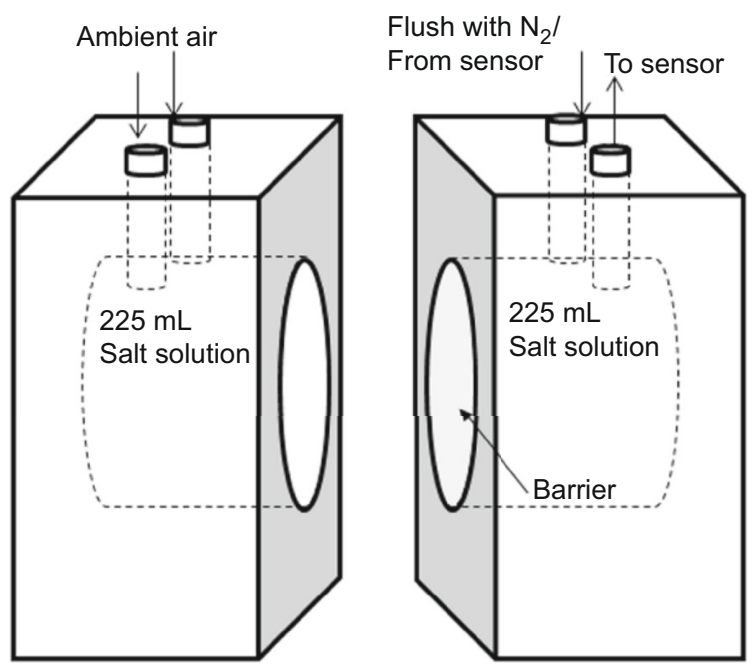

Fig. 2: Schematic diagram of the equipment used to make AOIR measurements

$\frac{l}{P}=\sum_{i} \frac{l_{i}}{P_{i}}$

where $l_{i}$ and $P_{i}$ are the thickness and permeability of the $i$ th layer ( 2 in this case, $i=1$ represents PET and $i=2$ represents the barrier coating).

\section{Characterization of the material}

\section{Fourier transform IR spectroscopy}

The FTIR spectra were collected with a Thermo Nicolet FTIR iS10 spectrometer (Madison, USA) in an attenuated total reflectance (ATR) mode using a diamond crystal, which gave a $0.3-\mu \mathrm{m}$ penetration depth at $3600 \mathrm{~cm}^{-1}$ (see Nyflött et al. ${ }^{54}$ for further details). The orientation of the clay was determined

from the FTIR spectra. The kaolin orientation factor, $\kappa$, can be calculated from the ratio of the peak intensity at $3695 \mathrm{~cm}^{-1}$ and the peak intensity at $3620 \mathrm{~cm}^{-1} 60$ thus:

$\kappa=\frac{\text { peak intensity } 3695 \mathrm{~cm}^{-1}}{\text { peak intensity } 3620 \mathrm{~cm}^{-1}}$.

Low $\kappa$ is interpreted as being the long axis of the kaolin platelets orientated in the basal plane of the substrate.

FTIR measurements were also taken to investigate the effect of humidity conditioning on the crystallinity of the samples based on PVOH. Several samples were first equilibrated at different RH using salt solutions, and the IR spectra that were collected were analyzed by monitoring the peaks in the region $1090-1140 \mathrm{~cm}^{-1}$. This region contains peaks $\left(\sim 1096\right.$ and $\left.\sim 1142 \mathrm{~cm}^{-1}\right)$ related to the amorphous and crystalline phases of the materials: They were resolved with peak area fits and used to determine the crystallinity as the ratio of the two peak areas.

\section{Differential scanning calorimetry}

Polymer crystallinity was also measured by a differential scanning calorimeter DSC (DSC Q2000, TA Instrument, Newcastle, USA) ${ }^{61}$ :

$\phi_{\mathrm{C}}(\%)=\frac{\Delta H_{\mathrm{f}}\left(T_{0}-T_{\mathrm{f}}\right)}{\Delta H_{\mathrm{f}}^{0}\left(T_{\mathrm{m}}\right)\left(1-m_{\mathrm{f}}\right)} \times 100 \%$

where $\Delta H_{\mathrm{f}}\left(T_{0}-T_{\mathrm{f}}\right)$ is the enthalpy of fusion of the sample between temperature $T_{0}$ and $T_{\mathrm{f}}, \Delta H_{\mathrm{f}}^{0}\left(T_{\mathrm{m}}\right)$ is the enthalpy of the $100 \%$ crystalline polymer and $m_{\mathrm{f}}$ is the mass fraction of the filler. For PVOH, the enthalpy of the totally crystalline polymer is $\Delta H_{\mathrm{f}}^{0}\left(T_{\mathrm{m}}\right)=138.6$ $\mathrm{J} \mathrm{g}^{-1}$. $^{62}$ The crystallinity of PVOH measured by a DSC has been reported to be in good agreement with that measured by X-ray diffraction (XRD) at low water 


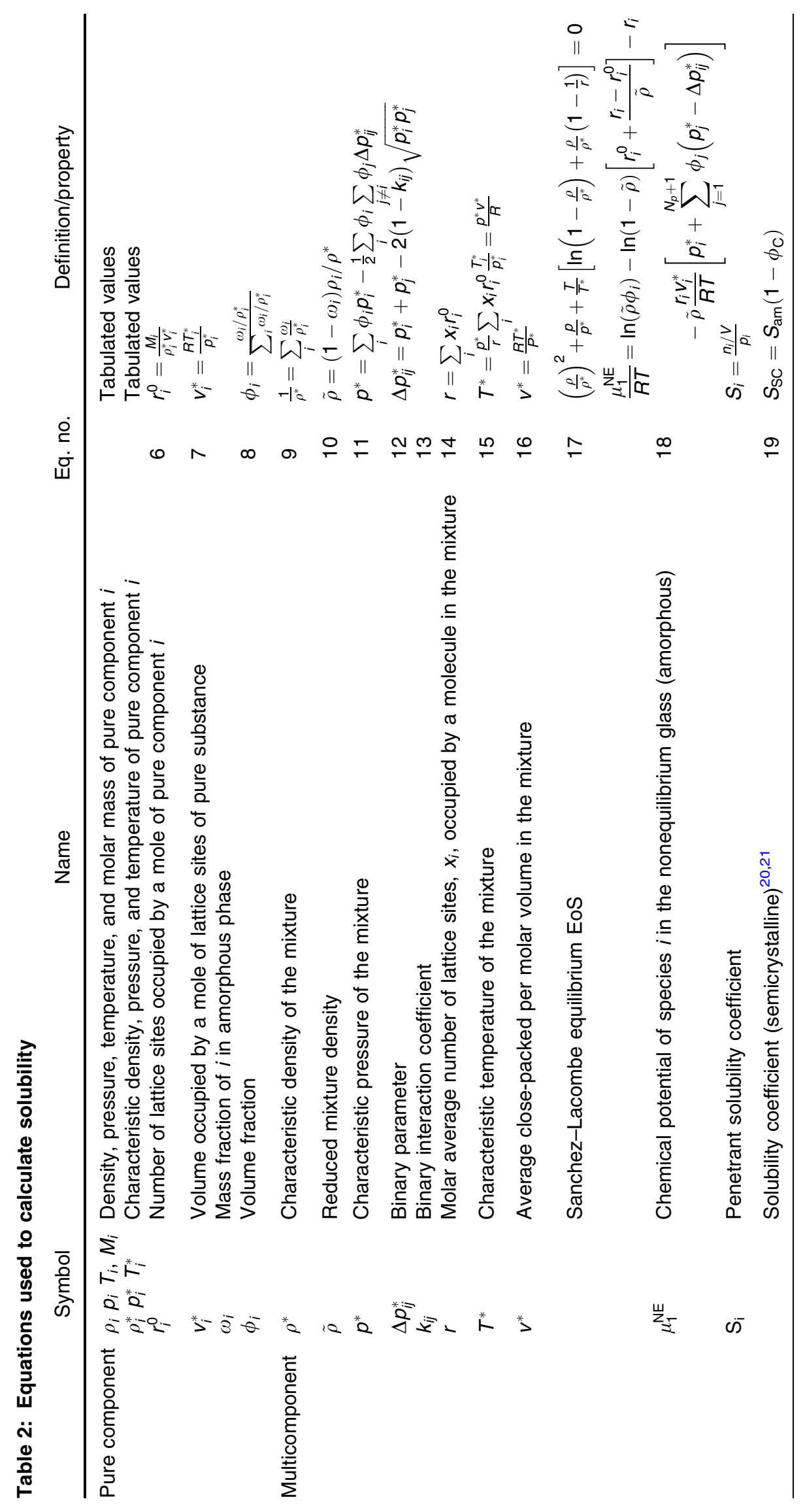


Table 3: Equations used to calculate diffusion and permeability

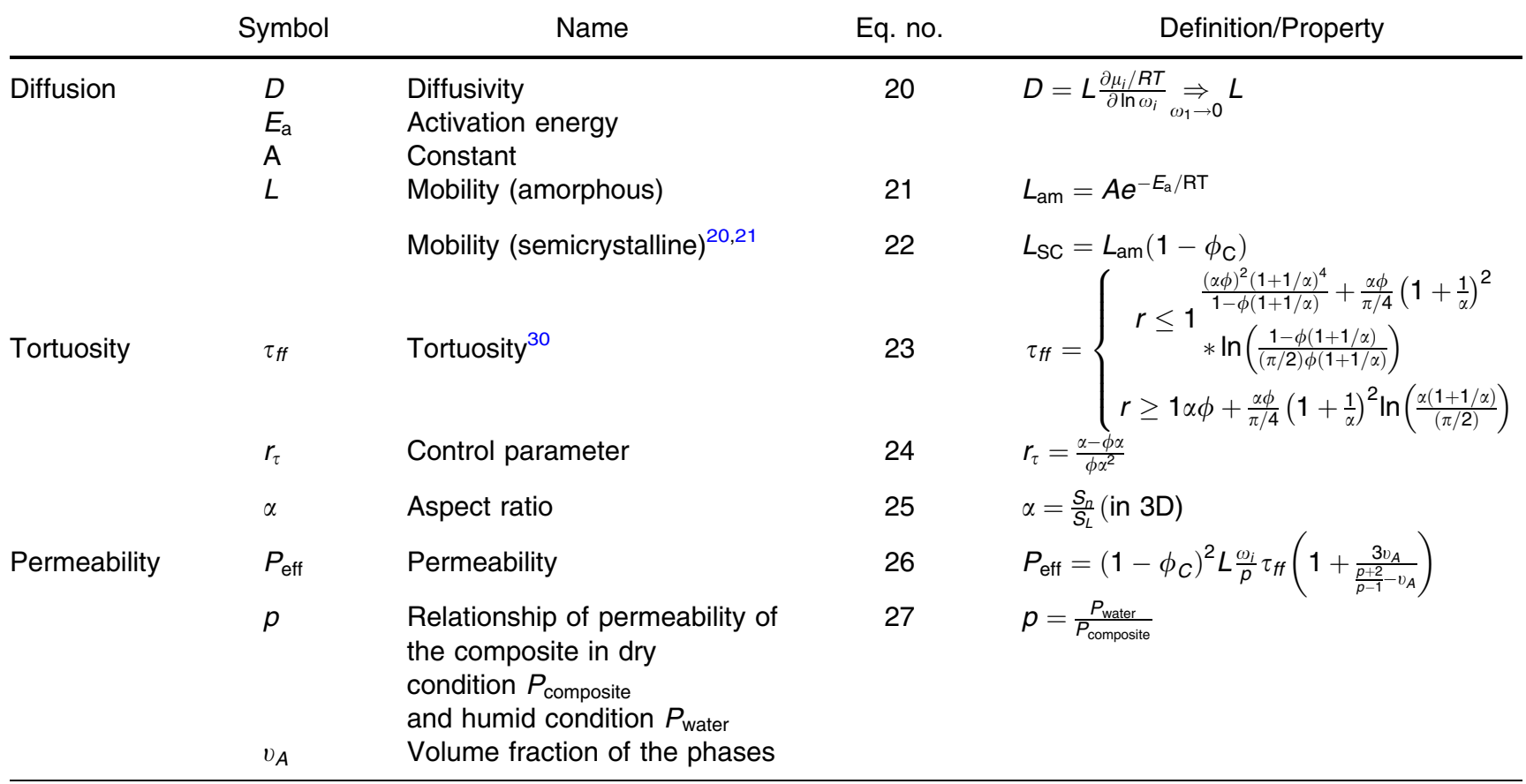

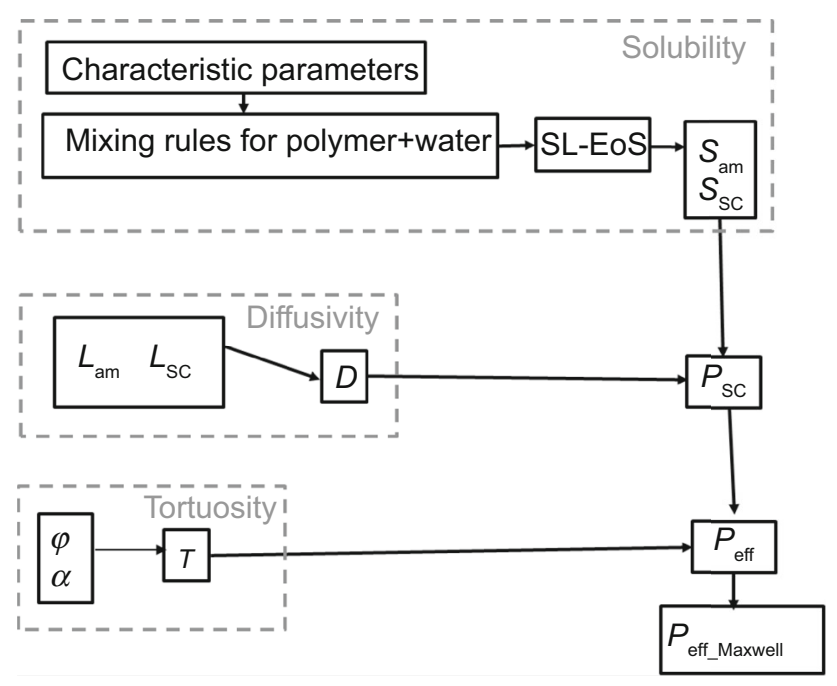

Fig. 3: Flow diagram of the modeling strategy, equations can be found in Tables 2 and 3. Subscript: am = amorphous, $\mathrm{SC}=$ semicrystalline, eff $=$ effective, meaning all components

content $^{61}$ and measured by FTIR at constant water content. $^{52}$ The films were removed from the PET substrate to be preconditioned at 20,50 , and $80 \% \mathrm{RH}$ for $8 \mathrm{~h}$ prior to the DSC measurements being made and placed in pans. The samples in the hermetically sealed pans were equilibrated at $35^{\circ} \mathrm{C}$ for $0.5 \mathrm{~min}$, and the temperature was raised from 35 to $250^{\circ} \mathrm{C}$ at a rate of $5^{\circ} \mathrm{C} \mathrm{min}-1$, with the temperature modulated by $\pm 0.796^{\circ} \mathrm{C}$ every $30 \mathrm{~s}$.

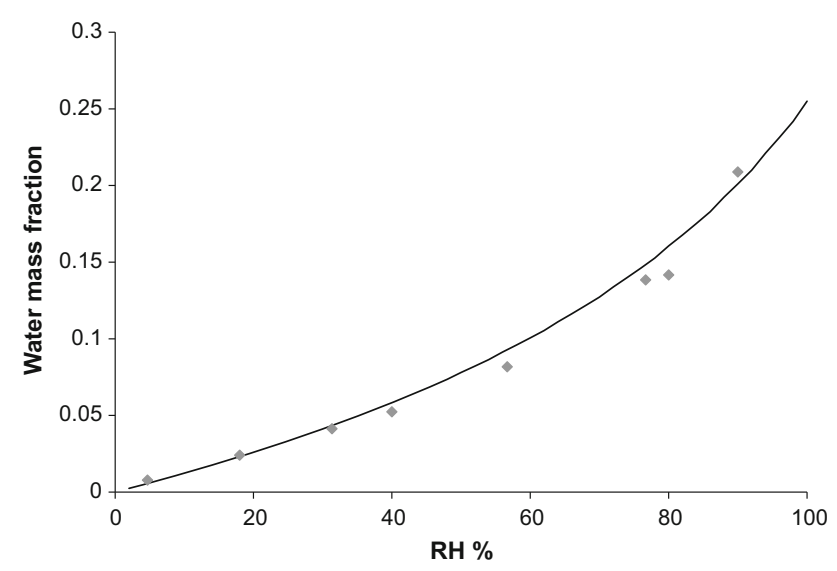

Fig. 4: Water solubility in the amorphous fraction of PVOH. Rhombus: experimental data from Tadokoro, et al. ${ }^{63}$ at the measurement temperature $\left(T=25^{\circ} \mathrm{C}\right)$; line: data calculated using Sanchez and Lacombe EoS

\section{Permeability model}

The permeability model previously described ${ }^{16}$ was used to calculate barrier performance of flake-filled semicrystalline polymer coatings. The model is now expanded further so that it can also capture the effect of humidity on mass transport in such material. The presence of water in the polymer samples can be accounted for in the thermodynamic analysis of the system, which describes the effect it has on crystallinity and diffusivity. For the sake of clarity, the model is summarized in Tables 2 and 3; Equations 9-16 are 


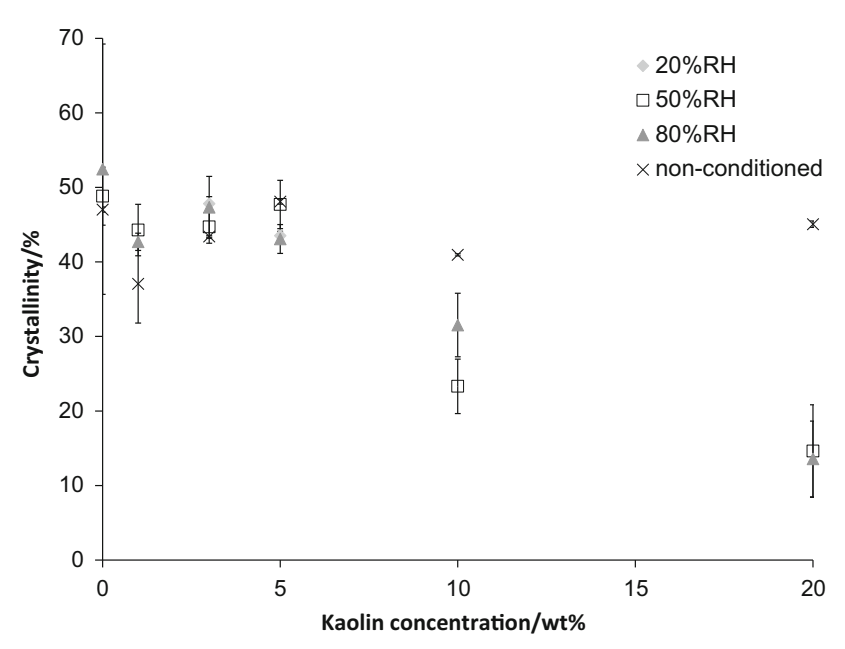

Fig. 5: Crystallinity of the polymer phase, measured by DSC, for samples with varying concentrations of kaolin and conditioned at different $\mathbf{R H}$

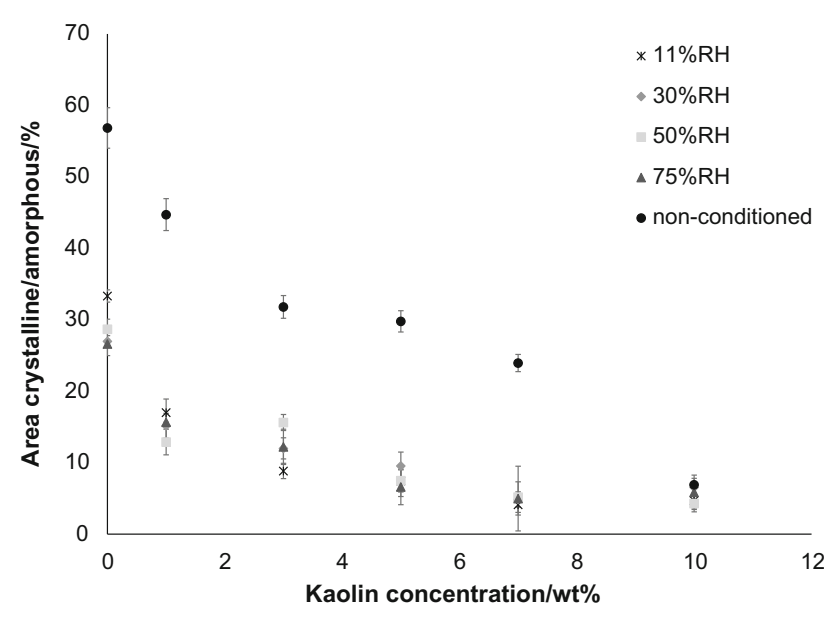

Fig. 6: Crystalline peak area divided by the amorphous peak area, determined by FTIR, for samples with varying concentrations of kaolin and conditioned at different $\mathrm{RH}$

included because of the addition of the influence of water (Fig. 3).

The analysis of water solubility in $\mathrm{PVOH}$, based on data after Tadokoro et al. ${ }^{63}$ illustrated in Fig. 4, suggested that the addition of water induced a glass transition in the $\mathrm{PVOH}$ phase, even at low activity values, at the measurement temperature $\left(T=25^{\circ} \mathrm{C}\right)$. Since water acts as a plasticizer of $\mathrm{PVOH}^{64}$ the mixture can be treated as being at thermodynamic equilibrium in a reasonably wide range of activities. ${ }^{65}$ The water solubility can therefore be described by the equilibrium known as the Sanchez and Lacombe equation of state (EoS). The curve obtained in Fig. 4 was used to retrieve the values of the mass fraction of water in the polymer film at the $\mathrm{RH}$ at which the experiments were performed: $0,20,50$, and $80 \% \mathrm{RH}$.

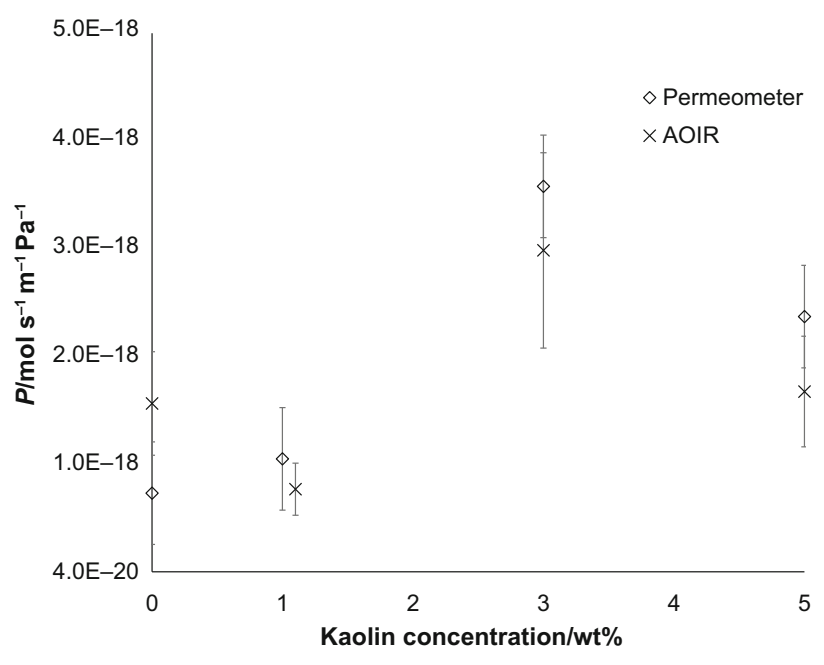

Fig. 7: Comparison of the different methods used to evaluate permeability at $50 \% \mathrm{RH}$ and $35^{\circ} \mathrm{C}$

For sake of simplicity, the mixture of PVOH and water was then treated as a single component at each specific $\mathrm{RH}$ : The pure characteristic parameters of this pseudocomponent were determined by the Sanchez and Lacombe EoS and the Sanchez and Lacombe mixing rules of the EoS (Equations 6-17). These parameters were evaluated and used in the calculation of the solubility of the oxygen in the film.

The polymer phase at high humidity has a higher degree of mobility, which leads to the penetrant diffusing faster. This can be described by the binary Maxwell equation. Although this equation is derived at infinite dilution (when $v_{A} \rightarrow 0$ ) and for spherical particles, it has nevertheless been proven to be useful for higher concentrations as well as for other types of particles. ${ }^{6-68}$

\section{Results and discussion}

\section{Characterization of the material}

The crystallinity of the various samples at different levels of RH showed values ranging from $10 \%$ to $60 \%$, depending mainly on the concentration of kaolin, as shown in Fig. 5. The nonconditioned samples (i.e., in dry conditions) showed higher crystallinity, between 36 and $47 \%$, and a weak dependence on the content of kaolin, Fig. 5. The conditioned samples, on the other hand, showed a decrease in crystalline content, which was particularly relevant when the kaolin had a concentration of $10 \%$ or above. A clear decrease in the crystallinity of the conditioned sample was indeed evident in this range. Interestingly, the barrier films appear to be more water sensitive when kaolin is present; larger depressions in the crystalline contents are observed at increasing RH. Humidity promotes the breakdown of crystalline regions, since water mole- 
cules diffuse into these regions and weaken the hydrogen bonds, eventually dissolving the crystals. ${ }^{69}$ The water melts polymer crystallites, which is a reversible process under removal of water. The decrease in the size of the crystalline regions caused by water was also observed clearly by the FTIR measurements, and the results of which are illustrated in Fig. 6. When crystallinity is measured by ATRFTIR, only the vibrational modes at the surface of the samples are accessed, whereas the DSC method probes the whole sample. This explains the slightly different results that were obtained by these two methods.

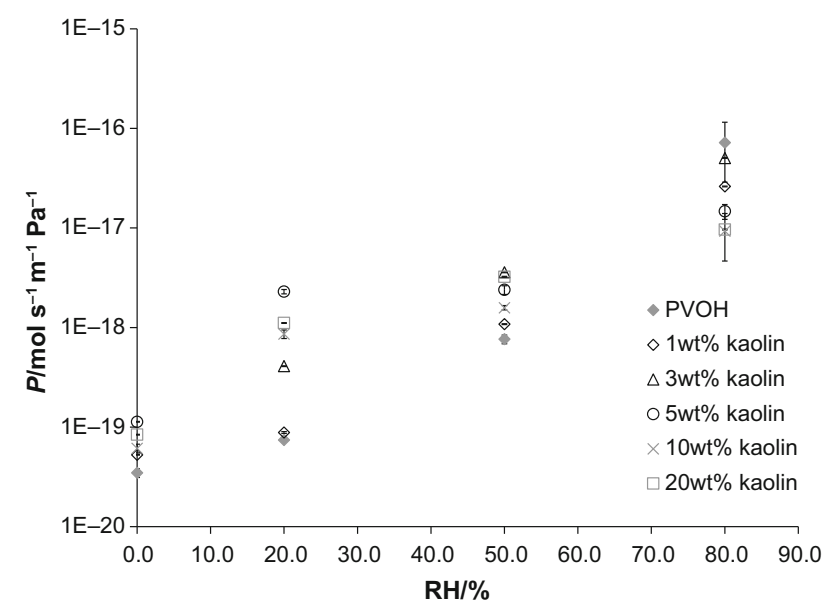

Fig. 8: Experimentally determined permeability vs RH presented on a log scale. The error bars indicate the SD

\section{Permeability}

The oxygen permeability of the pure coatings was evaluated using the resistance formula, and the results are given in Fig. 7. The plot presents a substantial agreement between the data obtained by different measurement techniques, even if there is a slight scattering present. The permeability measured by the two different methods is then summarized in the combined plot in Fig. 8. In the calculation of the barrier coating alone, equation (3), the permeability of PET substrate was treated independently of RH. However, it is a known fact that the permeability of oxygen through PET varies slightly with water content. $^{70}$ Figure 8 shows the results of the samples containing only PVOH and the mixture of PVOH: 10 $\mathrm{wt} \%$ kaolin measured with the AOIR instrument. The permeability values at $0 \% \mathrm{RH}$ (excluding $\mathrm{PVOH}$ and the mixture of PVOH:10 wt\% kaolin) were measured by the manometric permeometer. As can be seen, the addition of kaolin increases the permeability of the gas compared to only $\mathrm{PVOH}$, up to $50 \% \mathrm{RH}$. This indicates that kaolin introduces microvoids into the material, thus lowering the overall barrier effect. On the other hand, the presence of moisture increases the $\mathrm{O}_{2}$ permeability significantly, which is the result of the plasticizing effect had by the water molecules and makes the polymer chains produced by the interaction with water molecules more flexible. The overall behavior shows that an initial increase in permeability was followed by levelling at higher concentrations of kaolin except for the highest level of humidity, at

Table 4: Data of the parameters used in the model, from literature or calculated

\begin{tabular}{|c|c|c|c|}
\hline Parameter & Value & Units & References \\
\hline$\rho_{\text {PVOH }}$ (amorphous) & 1.12 & $\mathrm{~g} \mathrm{~cm}^{-3}$ & 60 \\
\hline$M_{\mathrm{O}_{2}}$ & 32 & $\mathrm{~g} \mathrm{~mol}^{-1}$ & \\
\hline$L_{0}$ (amorphous $\mathrm{PVOH}$ ) & $1 \times 10^{-11}(H=98 \%)$ & $\mathrm{cm}^{2} \mathrm{~s}^{-1}$ & 61 \\
\hline$T^{*} \mathrm{PVOH}+$ water & $\begin{array}{l}511(20 \% \mathrm{RH}) \\
483(50 \% \mathrm{RH}) \\
457(80 \% \mathrm{RH})\end{array}$ & $\mathrm{K}$ & This work \\
\hline $\begin{array}{l}T^{*} \mathrm{O}_{2} \\
\rho^{*} \mathrm{PVOH}+\text { water }\end{array}$ & $\begin{array}{l}170 \\
1.49(20 \% \mathrm{RH}) \\
1.44(50 \% \mathrm{RH}) \\
1.39(80 \% \mathrm{RH})\end{array}$ & $\begin{array}{l}\mathrm{K} \\
\mathrm{kg} \mathrm{m}^{-3}\end{array}$ & $\begin{array}{l}62 \\
\text { This work }\end{array}$ \\
\hline $\begin{array}{l}\rho^{*} \mathrm{O}_{2} \\
p^{*} \mathrm{PVOH}+\text { water }\end{array}$ & $\begin{array}{l}1.29 \\
2851(20 \% \mathrm{RH}) \\
2785(50 \% \mathrm{RH}) \\
2722(80 \% \mathrm{RH})\end{array}$ & $\begin{array}{l}\mathrm{kg} \mathrm{m}^{-3} \\
\mathrm{MPa}\end{array}$ & $\begin{array}{l}62 \\
\text { This work }\end{array}$ \\
\hline $\begin{array}{l}p^{*} \mathrm{O}_{2} \\
p\end{array}$ & $\begin{array}{l}280 \\
1000(20 \% \mathrm{RH}) \\
2500(50 \% \mathrm{RH}) \\
4000(80 \% \mathrm{RH})\end{array}$ & $\mathrm{MPa}$ & $\begin{array}{l}62 \\
\text { This work }\end{array}$ \\
\hline$v_{A}$ & $\begin{array}{l}0.2(20 \% \mathrm{RH}) \\
0.5(50 \% \mathrm{RH}) \\
0.8(80 \% \mathrm{RH})\end{array}$ & & This work \\
\hline
\end{tabular}




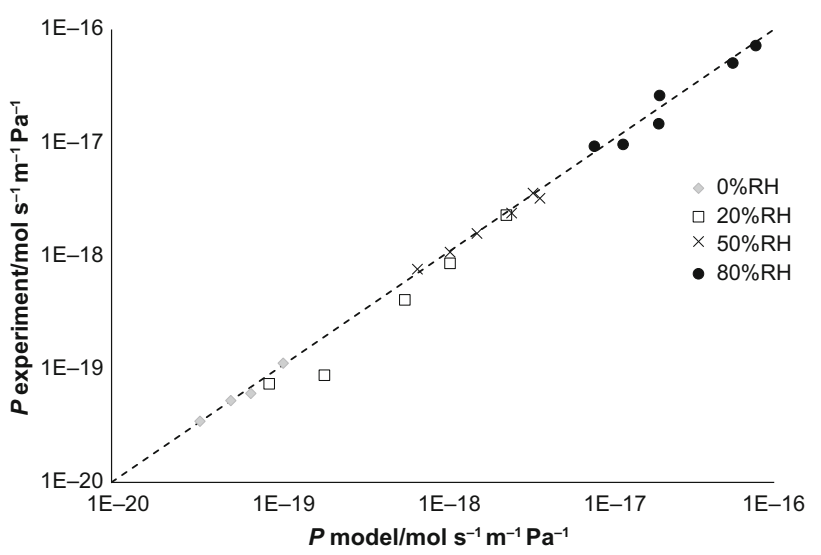

Fig. 9: Parity plot between the permeability determined experimentally (presented in Fig. 8) and that obtained from the model for kaolin contents of $0,1,3,5,10$, and 20 wt $\%$

which no significant influence of clay loading could be detected on permeability. Although PVOH coating is a good oxygen barrier at low $\mathrm{RH}$, this function is completely lost at $80 \% \mathrm{RH}$ due to the water sensitivity of PVOH, as shown elsewhere. ${ }^{71-74}$

\section{Modeling permeability}

The previous approach was modified to include the effect of humidity on the oxygen permeability model for the barrier coating. The moisture is included by adding the pseudocomponent in the solubility and the binary Maxwell equation in the diffusivity (equation 26). The parameters of the pseudocomponent, i.e., $\mathrm{PVOH}+$ water, are calculated according to Sanchez and Lacombe's mixing rules. ${ }^{19}$ The parameters calculated using the Sanchez Lacombe EoS are summarized in Table 4 and used further in the permeation model. It is quite remarkable that the new model shows very good agreement with the experimental results, as illustrated in Fig. 9. Figures 5 and 6 show that the degree of crystallinity varies significantly at the different RH, and such changes need to be considered in the modeling analysis. The size of the crystallites is not explicitly considered, but only its volumetric fraction, in the hypothesis that crystallites are small enough to neglect any macroscopic effect, and not considering any interaction between amorphous and crystalline region. The discrepancies observed for some experimental points, especially at $20 \% \mathrm{RH}$, can be due to a slight difference in crystallinity due to plasticization induced by the water molecules. The combined model for $20 \% \mathrm{RH}$ showed lower permeability than the experimental data, which is probably due to an underestimation of the solubility of the water as well as to the increase in diffusivity induced by the water (i.e., the mobility of the polymer chains). This combined model is able to represent the behavior of oxygen permeation through complex, filled, polymer layers at humid conditions.

\section{Conclusions}

The permeability of oxygen gas is expected to depend on both crystallinity and concentration of kaolin, as well as the surrounding conditions. This study has shown that the barrier capacity of oxygen in kaolinfilled PVOH film deteriorates as humidity is increased. Moreover, the kaolin hinders the proper formation of PVOH crystals and, consequently, no enhancement of the barrier coating properties was observed at $\mathrm{RH}$ values below $80 \%$. At extremely high humidity ( $80 \% \mathrm{RH})$, however, the filler was able to improve the barrier properties appreciably. Lower levels of $\mathrm{O}_{2}$ permeability were measured at higher kaolin concentrations due to PVOH being solved in the water.

The permeability measurements of the coatings were taken in the further development of a permeability model for filled polymeric layer described previously, which includes the ability to account also for the effect of humidity. The model showed good agreement with the experiments; it improves not only understanding of barrier performance but also how permeability is related to both filler content and $\mathrm{RH}$ in particular.

Acknowledgments This study was performed within the multidisciplinary Industrial Graduate School VIPP (www.kau.se/en/vipp) —Values Created in Fibre-Based Processes and Products-at Karlstad University, Sweden, with the financial support of the Knowledge Foundation, Sweden (Reference Number: 20100268) and Stora Enso. The authors would also like to acknowledge the foundation Stiftelsen Disponent och Fru Christian Storjohanns Stipendiefond for financing received during secondment at DICAM, Bologna, Italy.

Open Access This article is distributed under the terms of the Creative Commons Attribution 4.0 International License (http://creativecommons.org/licenses/by/4.0/), which permits unrestricted use, distribution, and reproduction in any medium, provided you give appropriate credit to the original author(s) and the source, provide a link to the Creative Commons license, and indicate if changes were made.

\section{References}

1. Alexander Stern, S, "Polymers for Gas Separations: The Next Decade." J. Membr. Sci., 94 (1) 1-65 (1994)

2. Andersson, C, "New Ways to Enhance the Functionality of Paperboard by Surface Treatment-A Review." Packag. Technol. Sci., 21 (6) 339-373 (2008) 
3. Lopez-Cervantes, J, Sanchez-Machado, DI, Pastorelli, S, Rijk, R, Paseiro-Losada, P, "Evaluating the Migration of Ingredients from Active Packaging and Development of Dedicated Methods: A Study of Two Iron-Based Oxygen Absorbers." Food Addit. Contam., 20 (3) 291-299 (2003)

4. Huis in't Veld, JHJ, "Microbial and Biochemical Spoilage of Foods: An Overview." Int. J. Food Microbiol., 33 (1) 1-18 (1996)

5. Guynot, ME, Sanchis, V, Ramos, AJ, Marín, S, "Mold-Free Shelf-Life Extension of Bakery Products by Active Packaging." J. Food Sci., 68 (8) 2547-2552 (2003)

6. Cui, Y, Kumar, S, Rao Kona, B, Van Houcke, D, "Gas Barrier Properties of Polymer/Clay Nanocomposites." RSC Adv., 5 (78) 63669-63690 (2015)

7. Lagaron, JM, Nunez, E, "Nanocomposites of MoistureSensitive Polymers and Biopolymers with Enhanced Performance for Flexible Packaging Applications." J. Plast. Film Sheeting, 28 (1) 79-89 (2012)

8. Arora, A, Padua, GW, "Review: Nanocomposites in Food Packaging." J. Food Sci., 75 (1) R43-R49 (2010)

9. De Azeredo, HMC, "Nanocomposites for Food Packaging Applications." Food Res. Int., 42 (9) 1240-1253 (2009)

10. Ray, S, Quek, SY, Easteal, A, Chen, XD, “The Potential Use of Polymer-Clay Nanocomposites in Food Packaging." Int. J. Food Eng. (2006). doi:10.2202/1556-3758.1149

11. Rhim, JW, Park, HM, Ha, CS, "Bio-Nanocomposites for Food Packaging Applications." Prog. Polym. Sci., 38 (10-11) 1629-1652 (2013)

12. Johansson, C, Bras, J, Mondragon, I, Nechita, P, Plackett, D, Simon, P, Svetec, DG, Virtanen, S, Baschetti, MG, Breen, C, Clegg, F, Aucejo, S, "Renewable Fibers and Bio-Based Materials for Packaging Applications-A Review of Recent Developments." Bioresources, 7 (2) 2506-2552 (2012)

13. Bollström, R, Nyqvist, R, Preston, J, Salminen, P, Toivakka, M, "Barrier Properties Created by Dispersion Coating." Tappi J., 12 (4) 45-51 (2013)

14. Solovyov, S, Goldman, A, Mass Transport and Reactive Barriers in Packaging: Theory, Applications, and Design. DEStech Pub., Lancaster, 2008

15. Johansson, C, Clegg, F, "Hydrophobically Modified Poly(vinyl alcohol) and Bentonite Nanocomposites Thereof: Barrier, Mechanical, and Aesthetic Properties." J. Appl. Polym. Sci. (2015). doi:10.1002/app.41737

16. Nyflött, A, Petkova-Olsson, Y, Moons, E, Bonnerup, C, Järnström, L, Carlsson, G, Lestelius, M, Minelli, M, "Modelling of Oxygen Permeation Through Filler-Supplemented Polymeric Layers for Barrier Coatings." J. Appl. Polym. Sci. (2017). doi:10.1002/app.44834

17. Doghieri, F, Sarti, GC, "Nonequilibrium Lattice Fluids: A Predictive Model for the Solubility in Glassy Polymers." Macromolecules, 29 (24) 7885-7896 (1996)

18. Giacinti Baschetti, M, De Angelis, MG, Doghieri, F, Sarti, GC, "Solubility of Gases in Polymeric Membranes." In: Chemical Engineering: Trends and Developments, pp. 41-61. John Wiley \& Sons, Ltd., Chichester, 2005

19. Sanchez, IC, Lacombe, RH, "Statistical Thermodynamics of Polymer Solutions." Macromolecules, 11 (6) 1145-1156(1978)

20. Minelli, M, "Modeling CO2 Solubility and Transport in Poly(ethylene terephthalate) Above and Below the Glass Transition." J. Membr. Sci., 451 305-311 (2014)

21. Minelli, M, Sarti, GC, "Permeability and Solubility of Carbon Dioxide in Different Glassy Polymer Systems With and Without Plasticization." J. Membr. Sci., 444 429-439 (2013)

22. Minelli, M, Sarti, GC, "Permeability and Diffusivity of $\mathrm{CO}_{2}$ in Glassy Polymers With and Without Plasticization." $J$. Membr. Sci., 435 176-185 (2013)
23. Minelli, M, Cocchi, G, Ansaloni, L, Baschetti, MG, De Angelis, MG, Doghieri, F, "Vapor and Liquid Sorption in Matrimid Polyimide: Experimental Characterization and Modeling." Ind. Eng. Chem. Res., 52 (26) 8936-8945 (2013)

24. Minelli, M, Doghieri, F, "A Predictive Model for Vapor Solubility and Volume Dilation in Glassy Polymers." Ind. Eng. Chem. Res., 51 (50) 16505-16516 (2012)

25. Davis, EM, Minelli, M, Baschetti, MG, Sarti, GC, Elabd, YA, "Nonequilibrium Sorption of Water in Polylactide." Macromolecules, 45 (18) 7486-7494 (2012)

26. Minelli, M, Doghieri, F, A Predictive Model for Solubility of Gases and Vapors in Swelling Glassy Polymers. Proc, Minneapolis, MN, 2011

27. De Angelis, MG, Sarti, GC, Doghieri, F, "NELF Model Prediction of the Infinite Dilution Gas Solubility in Glassy Polymers." J. Membr. Sci., 289 (1-2) 106-122 (2007)

28. Barrer, RM, "Diffusion and Permeation in Heterogeneous Media." In: Crank, J, Park, GS (eds.) Diffusion in Polymers, pp. 165-217. Academic Press, New York (1968)

29. Felder, RM, Huvard, GS, "17. Permeation, Diffusion, and Sorption of Gases and Vapors." In: Fava, RA (ed.) Methods in Experimental Physics, vol. 16, pp 315-377. Academic Press (1980). doi:10.1016/S0076-695X(08)60536-0

30. Cussler, EL, Aris, R, Hughes, SE, Ward Iii, WJ, "Barrier Membranes." J. Membr. Sci., 38 (2) 161-174 (1988)

31. Kamal, MR, Jinnah, IA, Utracki, LA, "Permeability of Oxygen and Water Vapor Through Polyethylene/Polyamide Films." Polym. Eng. Sci., 24 (17) 1337-1347 (1984)

32. Perry, D, Ward, WJ, Cussler, EL, "Unsteady Diffusion in Barrier Membranes." J. Membr. Sci., 44 (2-3) 305-311 (1989)

33. Eitzman, DM, Melkote, RR, Cussler, EL, "Barrier Membranes with Tipped Impermeable Flakes." AIChE J., 42 (1) 2-9 (1996)

34. Falla, WR, Mulski, M, Cussler, EL, "Estimating Diffusion Through Flake-Filled Membranes.” J. Membr. Sci., 119 (1) 129-138 (1996)

35. Wakeham, WA, Mason, EA, "Diffusion Through Multiperforate Laminae." Ind. Eng. Chem. Fundam., 18 (4) 301-305 (1979)

36. Aris, R, "On a Problem in Hindered Diffusion." Arch. Ration. Mech. Anal., 95 (2) 83-91 (1986)

37. Fredrickson, GH, Bicerano, J, "Barrier Properties of Oriented Disk Composites.' J. Chem. Phys., 110 (4) 2181-2188 (1999)

38. Gusev, AA, Lusti, HR, "Rational Design of Nanocomposites for Barrier Applications." Adv. Mater., 13 (21) 1641-1643 (2001)

39. Lape, NK, Nuxoll, EE, Cussler, EL, "Polydisperse Flakes in Barrier Films.” J. Membr. Sci., 236 (1-2) 29-37 (2004)

40. Yang, C, Smyrl, WH, Cussler, EL, "Flake Alignment in Composite Coatings." J. Membr. Sci., 231 (1-2) 1-12 (2004)

41. Chen, X, Papathanasiou, TD, "Barrier Properties of FlakeFilled Membranes: Review and Numerical Evaluation." $J$. Plast. Film Sheeting, 23 (4) 319-345 (2007)

42. Swannack, C, Cox, C, Liakos, A, Hirt, D, "A ThreeDimensional Simulation of Barrier Properties of Nanocomposite Films." J. Membr. Sci., 263 47-56 (2005)

43. Minelli, M, Baschetti, MG, Doghieri, F, "A Comprehensive Model for mass Transport Properties in Nanocomposites." $J$. Membr. Sci., 381 (1-2) 10-20 (2011)

44. Kristensen, AH, Thorbjörn, A, Jensen, MP, Pedersen, M, Moldrup, P, "Gas-Phase Diffusivity and Tortuosity of Structured Soils." J. Contam. Hydrol., 115 (1-4) 26-33 (2010)

45. Moldrup, P, Olesen, T, Komatsu, T, Schjønning, P, Rolston, DE, "Tortuosity, Diffusivity, and Permeability in the Soil 
Liquid and Gaseous Phases." Soil Sci. Soc. Am. J., 65 (3) 613-623 (2001)

46. Maxwell, C, Treatise on Electricity and Magnetism. Clarendon, Oxford, 1904

47. Rayleigh, L, "On the Influence of Obstacles Arranged in Rectangular Order Upon the Properties of a Medium." Philos. Mag., 34 481-502 (1892)

48. Nielsen, LE, "Models for the Permeability of Filled Polymer Systems." J. Macromol. Sci. Chem., A1 (5) 929-942 (1967)

49. Lusti, HR, Gusev, AA, Guseva, O, "The Influence of Platelet Disorientation on the Barrier Properties of Composites: A Numerical Study." Model. Simul. Mater. Sci., 12 (6) 1201-1207 (2004)

50. Bharadwaj, RK, "Modeling the Barrier Properties of Polymer-Layered Silicate Nanocomposites." Macromolecules, 34 (26) 9189-9192 (2001)

51. Martinez-Hermosilla, GA, Mesic, B, Bronlund, JE, "A Review of Thermoplastic Composites Vapour Permeability Models: Applicability for Barrier Dispersion Coatings." Packag. Technol. Sci., 28 (7) 565-578 (2015)

52. Nyflött, $\AA$, Moons, E, Bonnerup, C, Carlsson, G, Järnström, L, Lestelius, M, "The Influence of Clay Orientation and Crystallinity on Oxygen Permeation in Dispersion Barrier Coatings." Appl. Clay Sci., 126 17-24 (2016)

53. Lee, L-H, "Relationships Between Surface Wettability and Glass Temperatures of High Polymers." J. Appl. Polym. Sci., 12 (4) 719-730 (1968)

54. Nyflött, ̊, Axrup, L, Carlsson, G, Järnström, L, Lestelius, M, Moons, E, Wahlström, T, "Influence of Kaolin Addition on the Dynamics of Oxygen Mass Transport in Polyvinyl Alcohol Dispersion Coatings." NPPRJ, 30 (3) 385-392 (2015)

55. Minelli, M, Baschetti, MG, Doghieri, F, Ankerfors, M, Lindström, T, Siro, I, Plackett, D, "Investigation of Mass Transport Properties of Microfibrillated Cellulose (MFC) Films." J. Membr. Sci., 358 (1-2) 67-75 (2010)

56. Minelli, M, De Angelis, MG, Doghieri, F, Marini, M, Toselli, M, Pilati, F, "Oxygen Permeability of Novel OrganicInorganic Coatings: I. Effects of Organic-Inorganic Ratio and Molecular Weight of the Organic Component." Eur. Polym. J., 44 (8) 2581-2588 (2008)

57. ASTM, "D 1434-82(2015)e1, Standard Test Method for Determining Gas Permeability Characteristics of Plastic Film and Sheeting." ASTM International, West Conshohocken, PA, 2015

58. Larsen, H, Kohler, A, Magnus, EM, "Ambient Oxygen Ingress Rate Method an Alternative Method to Ox-Tran for Measuring Oxygen Transmission Rate of Whole Packages." Packag. Technol. Sci., 13 (6) 233-241 (2000)

59. Minelli, M, De Angelis, MG, Doghieri, F, Rocchetti, M, Montenero, A, "Barrier Properties of Organic-Inorganic Hybrid Coatings Based on Polyvinyl Alcohol with Improved Water Resistance." Polym. Eng. Sci., 50 (1) 144-153 (2010)

60. Elton, NJ, Gate, LF, Hooper, JJ, "Texture and Orientation of Kaolin in Coatings." Clay Miner., 34 (1) 89-98 (1999)
61. Patel, AK, Bajpai, R, Keller, JM, "On the Crystallinity of PVA/Palm Leaf Biocomposite Using DSC and XRD Techniques." Microsyst. Technol., 20 (1) 41-49 (2014)

62. Peppas, NA, Merrill, EW, "Differential Scanning Calorimetry of Crystallized PVA Hydrogels." J. Appl. Polym. Sci., 20 (6) 1457-1465 (1976)

63. Tadokoro, H, Seki, S, Nitta, I, "The Crystallinity of Solid High Polymers. I. The Crystallinity of Polyvinyl Alcohol Film.” Bull. Chem. Soc. Jpn., 28 (8) 559-564 (1955)

64. Konidari, MV, Papadokostaki, KG, Sanopoulou, M, "Moisture-Induced Effects on the Tensile Mechanical Properties and Glass-Transition Temperature of Poly(vinyl alcohol) Films." J. Appl. Polym. Sci., 120 (6) 3381-3386 (2011)

65. Peppas, NA, "Infrared Spectroscopy of Semicrystalline Poly(vinyl alcohol) Networks." Macromol. Chem., 178 (2) 595-601 (1977)

66. Minelli, M, Doghieri, F, Papadokostaki, KG, Petropoulos, JH, "A Fundamental Study of the Extent of Meaningful Application of Maxwell's and Wiener's Equations to the Permeability of Binary Composite Materials. Part I: A Numerical Computation Approach." Chem. Eng. Sci., 104 630-637 (2013)

67. Petropoulos, JH, Papadokostaki, KG, Minelli, M, Doghieri, F, "On the Role of Diffusivity Ratio and Partition Coefficient in Diffusional Molecular Transport in Binary Composite Materials, with Special Reference to the Maxwell Equation." J. Membr. Sci., 456 162-166 (2014)

68. Papadokostaki, KG, Minelli, M, Doghieri, F, Petropoulos, JH, "A Fundamental Study of the Extent of Meaningful Application of Maxwell's and Wiener's Equations to the Permeability of Binary Composite Materials. Part II: A Useful Explicit Analytical Approach.” Chem. Eng. Sci., 131 353-359 (2015)

69. Finch, CA, Polyvinyl Alcohol: Properties and Applications. Wiley, Bristol, 1973

70. Auras, R, Harte, B, Selke, S, "Effect of Water on the Oxygen Barrier Properties of Poly(ethylene terephthalate) and Polylactide Films." J. Appl. Polym. Sci., 92 (3) 17901803 (2004)

71. Grunlan, JC, Grigorian, A, Hamilton, CB, Mehrabi, AR, "Effect of Clay Concentration on the Oxygen Permeability and Optical Properties of a Modified Poly(vinyl alcohol)." $J$. Appl. Polym. Sci., 93 (3) 1102 (2004)

72. Hauser, PM, McLaren, AD, "Permeation Through and Sorption of Water Vapor by High Polymers." Ind. Eng. Chem., 40 (1) 112-117 (1948)

73. Karlsson, GE, Gedde, UW, Hedenqvist, MS, "Molecular Dynamics Simulation of Oxygen Diffusion in Dry and Water-Containing Poly(vinyl alcohol)." Polymer, 45 (11) 3893-3900 (2004)

74. Hodge, RM, Edward, GH, Simon, GP, "Water Absorption and States of Water in Semicrystalline Poly(vinyl alcohol) Films." Polymer, 37 (8) 1371-1376 (1996) 